09.1

\title{
Кинетика фосфоресценции синглетного кислорода в клетках HeLa в суспензии
}

\author{
() В.П. Белик ${ }^{1}$, Д.М. Бельтюкова ${ }^{1, \uparrow, ~ Т . Н . ~ Б е л я е в а ~}{ }^{2}$, И.М. Гаджиев ${ }^{1}$, Е.С. Корнилова ${ }^{2}$, И.К. Литвинов ${ }^{2}$, \\ И.В. Семенова ${ }^{1}$, О.С. Васютинский ${ }^{1}$ \\ ${ }^{1}$ Физико-технический институт им. А.Ф. Иофрфе РАН, Санкт-Петербург, Россия \\ ${ }^{2}$ Институт цитологии РАН, Санкт-Петербург, Россия \\ E-mail: dina.beltukova@gmail.com
}

Поступило в Редакцию 6 июня 2019г.

В окончательной редакции 10 июня 2019г.

Принято к публикации 10 июня 2019 г.

\begin{abstract}
Исследована кинетика фосфоресценции синглетного кислорода в суспензии клеток HeLa в фосфатном буфере PBS при его фотосенсибилизированной генерации с использованием фотосенсибилизатора Радахлорин. Определены характерное время генерации синглетного кислорода и время его жизни в клетках. Анализ экспериментальных данных показал, что время жизни синглетного кислорода в клетках уменьшается по сравнению с временем жизни в растворах Радахлорина в PBS и воде, а время жизни триплетного состояния фотосенсибилизатора, наоборот, растет.
\end{abstract}

Ключевые слова: синглетный кислород, фотодинамическая терапия, фотосенсибилизатор Радахлорин, клетки HeLa.

DOI: 10.21883/PJTF.2019.18.48235.17910

Фотодинамическая терапия находит в настоящее время все более широкое применение в медицинской практике для лечения злокачественных новообразований, некоторых кожных и инфекционных заболеваний. Этот метод основан на фотосенсибилизированной генерации в целевых клетках и тканях активных форм кислорода, прежде всего синглетного кислорода (СК). Известно, что клетки обладают способностью противостоять относительно низким уровням СК за счет имеющихся внутриклеточных тушителей: каротиноидов, аминокислот, липидов и др. Таким образом, эффективность фотодинамической терапии напрямую зависит от количества генерируемого в клетках СК.

Как известно, фотосенсибилизаторы (ФС) разных типов накапливаются в различных клеточных компартментах, причем степень их накопления может варьироваться в зависимости от типа клеток и локализации в них. Кроме того, содержание кислорода в разных клетках и клеточных компартментах также неодинаково. Поэтому для оценки эффективности действия ФС в клетках того или иного типа помимо изучения процессов гибели клеток при фотодинамическом воздействии представляет большой интерес исследование процесса генерации в них СК. Прямым методом детектирования СК является регистрация его фосфоресценции на длине волны около $1270 \mathrm{~nm}$. Однако поскольку переход с возбужденного синглетного уровня молекулы кислорода в основное состояние запрещен несколькими правилами отбора, интенсивность сигнала фосфоресценции очень мала и его регистрация представляет серьезные трудности, в особенности в живых системах. Тем не менее к настоящему времени уже были проведены успешные экспе- риментальные исследования сигналов фосфоресценции СК в клетках в суспензиях [1-6], однако их результаты привели к противоречивым выводам, что стимулирует дальнейшие исследования в этой области. В частности, в работе [1] при наблюдении сигнала фосфоресценции CK в лейкемических клетках AML5 и P388 с использованием фталоцианинового ФС $\mathrm{AlS}_{4} \mathrm{Pc}$ было продемонстрировано существенное уменьшение времени жизни СК и увеличение времени жизни триплетного состояния ФС в клетках по сравнению с таковыми в водном растворе ФС. Уменьшение времени жизни СК было также зарегистрировано в клетках фибробластов кожи человека с использованием порфириновых ФС ТМРуР и TPPS [2]. В [3] авторы зарегистрировали уменьшение времени жизни СК в клетках Jurkat Т-лимфобластной лейкемии с использованием феофорбида А, а в [4] они обнаружили в той же комбинации клеток и ФС зависимость времени жизни СК от дозы облучения с увеличением вплоть до значений в воде и объяснили это истощением тушителей СК в клетках при более длительном облучении. В работе [5] при анализе кинетики фосфоресценции CK в клетках фибробластов 3T3 и HeLa при использовании фотосенсибилизаторов TPPS, TMPyP и PPIX были получены характерные времена нарастания и спада сигнала СК порядка 1 и $6 \mu$ s соответственно. При этом авторы предположили, что более короткое время соответствует времени жизни СК, а более длинное триплета ФС. В работе [6] оценка времени жизни СК в клетках HeLa, сенсибилизированных TMPyP, дала значение, близкое к времени жизни в воде.

Цель настоящей работы состоит в исследовании кинетики фосфоресценции и определении времени жизни СК 
в клетках линии HeLa при его фотосенсибилизированной генерации с использованием ФС хлоринового ряда Радахлорин (RadaPharma). Эксперименты проводились в суспензии клеток в фосфатном буфере PBS. Фотофизические свойства Радахлорина в водном растворе были детально исследованы нами ранее (см. [7-9]). В работах $[10,11]$ были представлены результаты исследования механизмов гибели клеток HeLa при использовании этого ФС.

Клеточные суспензии для анализа были получены следующим образом. Клетки аденокарциномы шейки матки линии HeLa (коллекция клеточных культур Института цитологии РАН, Санкт-Петербург) культивировали во флаконах $25 \mathrm{~cm}^{2}$ (Nunc, CША) в среде DMEM (Биолот, Россия), содержащей $20 \mathrm{mM}$ глютамина, 10\% сыворотки крови плодов коровы, $0.1 \%$ гентамицина в атмосфере $5 \% \mathrm{CO}_{2}$ при $37^{\circ} \mathrm{C}$. Эксперименты проводились через $48 \mathrm{~h}$ после посева при достижении культурами клеток $90 \%$ монослоя. За $24 \mathrm{~h}$ до проведения эксперимента в клеточную среду добавляли ФС Радахлорин в концентрации $20 \mu \mathrm{g} / \mathrm{ml}$ и продолжали инкубирование в этом растворе. Как было показано ранее [10,12], Радахлорин эффективно накапливается в клетках, в том числе в клеткаx HeLa, и приводит к их гибели при фотодинамическом воздействии $[10,11]$. Непосредственно перед проведением эксперимента из сосуда для выращивания клеток удалялась культуральная среда с фотосенсибилизатором, клетки промывали натрий-фосфатным буфером (PBS, pH 7.4) и затем добавляли раствор трипсин/версен $1: 1$ (Биолот) для открепления клеток от поверхности флакона. Открепившиеся клетки переносили в центрифужную пробирку. Небольшую часть раствора с клетками отбирали и использовали для оценки их количества. Подсчет клеток проводился с помощью камеры Фукса-Розенталя. Остальные клетки осаждали центрифугированием. Осажденные клетки ресуспендировали в PBS для получения $0.5 \mathrm{ml}$ клеточной взвеси. Типичное количество клеток в полученной суспензии составляло $(2-3) \cdot 10^{6} \mathrm{cell} / \mathrm{ml}$.

Полученная суспензия наливалась в кварцевую кювету с сечением $10 \times 10 \mathrm{~mm}^{2}$ и помещалась в экспериментальную установку. Схема установки приведена на рис. 1. Кювета (2) устанавливалась перед входным окном инфракрасного фотоэлектронного умножителя (ФЭУ) Hamamatsu NIR-PMT H10330B-45 (6), подключенного к модулю времякорреляционного счета фотонов TCSPC PicoHarp300 (PicoQuant) (7). Возбуждение фосфоресценции синглетного кислорода в клеточной взвеси производилось с помощью импульсного полупроводникового лазера (1) на длине волны $405 \mathrm{~nm}$, вблизи максимума полосы Soret поглощения фотосенсибилизатора. Длительность импульса составляла $100 \mathrm{~ns}$, частота повторения импульсов $100 \mathrm{kHz}$, средняя мощность лазерного излучения $3.5 \mathrm{~mW}$ при энергии в импульсе 35 nJ. Лазерный пучок проходил вблизи стенки кюветы, обращенной к ФЭУ, около дна кюветы, где концентрация клеток была максимальной.

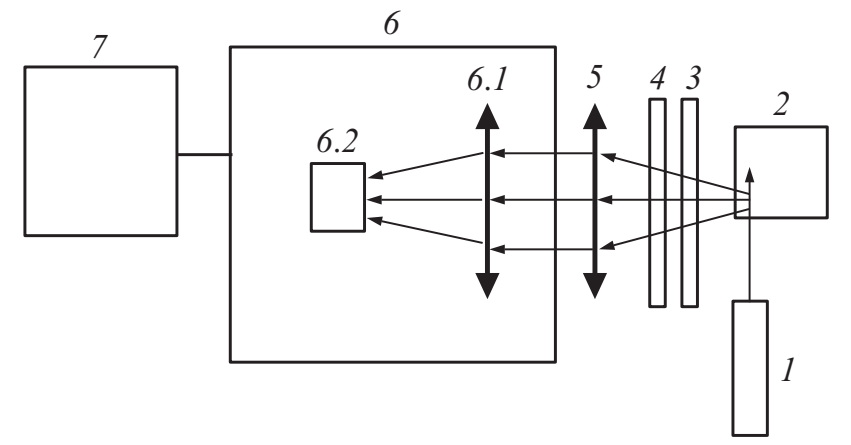

Рис. 1. Схема установки. 1 - возбуждающий лазер, $2-$ кварцевая кювета с исследуемым раствором, 3 - кремниевый фильтр, 4 - интерференционный фильтр, 5- собирающая линза, 6 - ФЭУ Hamamatsu (NIR-PMT H10330B-45), 6.1 - линза ФЭУ, 6.2 - фотокатод ФЭУ, 7 - модуль ТСРРС PicoHarp300 (PicoQuant).

Для эффективного сбора излучения фосфоресценции СК на длине волны около $1270 \mathrm{~nm}$ на входном окне ФЭУ была смонтирована оптическая схема, состоящая из собственной линзы ФЭУ $(6.1)$, фокусирующей излучение на круглый фотокатод ФЭУ (6.2) с эффективным диаметром $1.6 \mathrm{~mm}$, и коллиматорной линзы (5), в фокусе которой располагался источник излучения (кювета с исследуемым раствором). Линейное увеличение оптической схемы составляло 2.2 и при диаметре лазерного пучка $3 \mathrm{~mm}$ позволяло выделять светящийся объем $24.7 \mathrm{~mm}^{3}$ (или $24.7 \mu 1$ ), излучение из которого попадало на фотокатод. При этом при концентрации клеток в растворе объемом $0.5 \mathrm{ml}$ порядка $1 \cdot 10^{6}$ в зоне облучения оказывалось около $5 \cdot 10^{4}$ клеток.

Для выделения полосы люминесценции СК перед коллиматорной линзой помещался интерференционный фильтр (4) с центром на длине волны $1270 \mathrm{~nm}$, спектральной шириной полосы пропускания (FWHM) $10 \mathrm{~nm}$ и пропусканием в полосе $80 \%$. Для дополнительного обрезания вклада рассеянного излучения лазера и флуоресценции фотосенсибилизатора сразу за кюветой располагался кремниевый фильтр (3) с границей пропускания $1000 \mathrm{~nm}$ и пропусканием в области $1270 \mathrm{~nm}$ порядка 95\%. Регистрация кинетики фосфоресценции СК производилась с использованием техники счета фотонов с корреляцией по времени TCSPC, время накопления сигнала составляло 300-600 s.

На рис. 2, $а$ приведена полученная кинетика фосфоресценции CK в суспензии клеток HeLa. Для сравнения на рис. 2, $b$ приведена кинетика фосфоресценции СК в чистом растворе Радахлорина в $\mathrm{PBS}$ в концентрации $35 \mu \mathrm{g} / \mathrm{ml}$. Как видно, интенсивность сигнала фосфоресценции СК из суспензии клеток существенно ниже, чем из чистого раствора фотосенсибилизатора в PBS. Помимо разницы в концентрациях это можно объяснить также сильным тушением СК в клетках, которое, например, в условиях эксперимента [3] с клетками Jurkat было оценено в $85 \%$. 

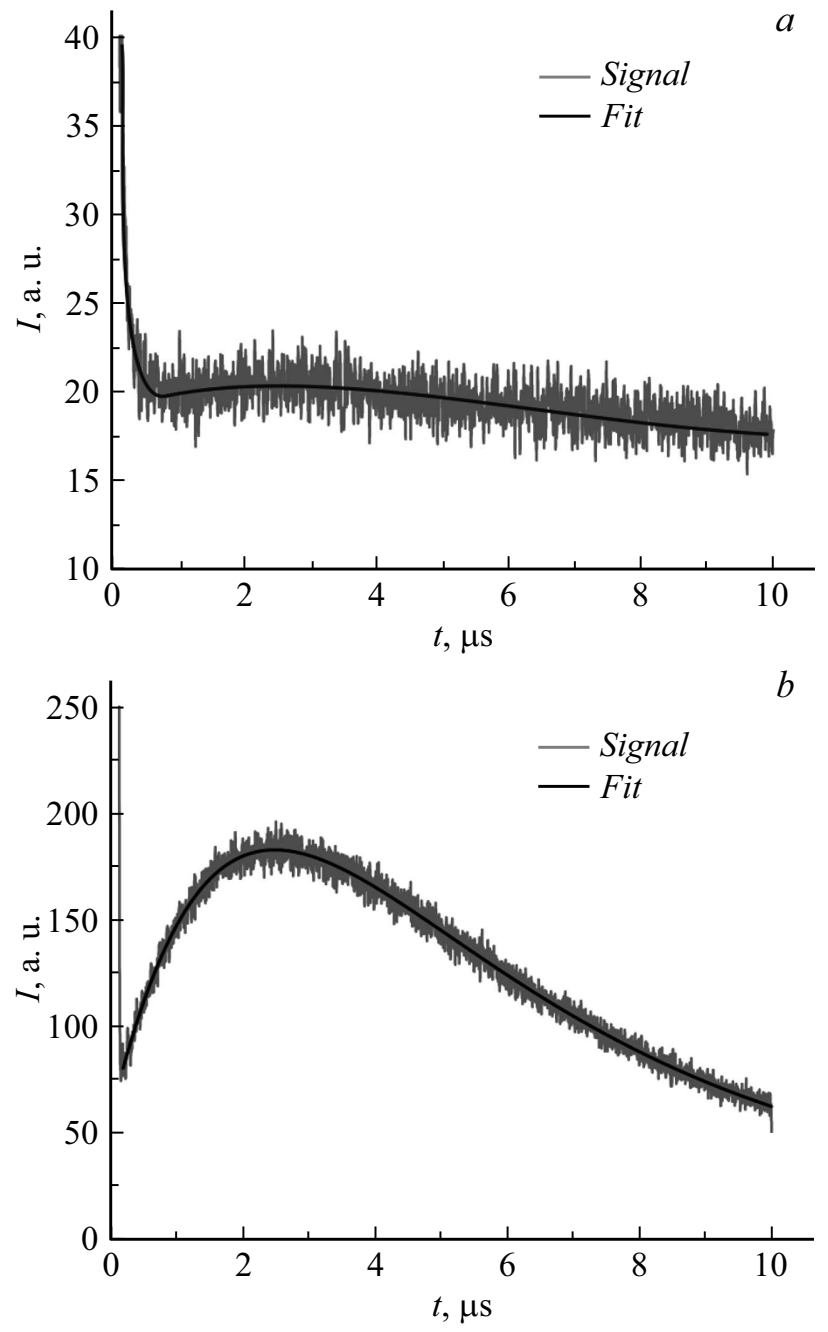

Рис. 2. $a-$ кинетика фосфоресценции синглетного кислорода в суспензии клеток HeLa; $b-$ кинетика фосфоресценции синглетного кислорода в растворе Радахлорина в PBS.

Подгонка полученных результатов проводилась на основе выражения [1]:

$$
I=C \frac{\tau_{2}}{\tau_{1}-\tau_{2}}\left(\exp \left(-\frac{t}{\tau_{1}}\right)-\exp \left(-\frac{t}{\tau_{2}}\right)\right)+B,
$$

где $C$ - константа, пропорциональная квантовому выходу СК, $\tau_{1}$ и $\tau_{2}$ - характерные времена нарастания и спада сигнала фосфоресценции СК, $B$ - константа, учитывающая темновой шум фотоприемника и возможное излучение засветки.

В результате подгонки полученных кривых были определены следующие значения времен в суспензии клеток HeLa: $\tau_{1}=3.8 \pm 0.2 \mu \mathrm{s}, \tau_{2}=1.3 \pm 0.2 \mu \mathrm{s}$. При этом в чистом растворе Радахлорина в PBS соответствующие времена были равны $\tau_{1}=1.9 \pm 0.2 \mu \mathrm{s}$ и $\tau_{2}=3.5 \pm 0.2 \mu \mathrm{s}$. Отметим, что значения для раствора Радахлорина в PBS близки к полученным нами ранее параметрам для раствора Радахлорина в воде [7]: $\tau_{1}=2.0 \pm 0.2 \mu \mathrm{s}, \tau_{2}=3.4 \pm 0.2 \mu \mathrm{s}$. Отметим, что урав- нение (1) инвариантно относительно одновременной перестановки параметров $\tau_{1}$ и $\tau_{2}$ в экспонентах и знаменателе предэкспоненциального множителя. Поэтому оно не позволяет однозначно соотнести полученные в результате подгонки кинетик фосфоресценции времена $\tau_{1}$ и $\tau_{2}$ с временами жизни триплета ФС и СК. Однако, основываясь на результатах работ $[1,4]$, можно сделать вывод, что в условиях нашего эксперимента $\tau_{1}$ соответствует времени жизни триплетного уровня ФС, а $\tau_{2}$ - времени жизни СК. Таким образом, можно утверждать, что при генерации СК в клетках HeLa, фотосенсибилизированных Радахлорином, наблюдается существенное увеличение времени жизни триплетного уровня ФС (с 2 до $3.8 \mu \mathrm{s})$ и уменьшение времени жизни CK (с 3.4 до $1.3 \mu \mathrm{s}$ ) по сравнению с соответствующими временами в растворах ФС в воде и $\mathrm{PBS}$.

Таким образом, в работе зарегистрирован сигнал фосфоресценции СК, возбуждаемого в суспензии живых клеток линии HeLa, сенсибилизированных Радахлорином. Амплитуда полученного сигнала оказалась существенно меньше амплитуды сигнала фосфоресценции СК в чистом растворе Радахлорина в PBS в концентрации $35 \mu \mathrm{g} / \mathrm{ml}$, что в основном обусловлено существенно меньшей концентрацией ФС, которую удается обеспечить внутри клеток HeLa по сравнению с концентрацией в чистом растворе, а также более сильным тушением СК в клетках по сравнению с чистым раствором. Исследована кинетика фосфоресценции с высоким временны́м разрешением и определены характерное время генерации и время жизни синглетного кислорода в клетках. Сделан вывод, что время жизни синглетного кислорода в клетках уменьшается по сравнению с временами жизни в растворах Радахлорина в $\mathrm{PBS}$ и воде, а время жизни триплетного состояния фотосенсибилизатора, наоборот, растет. Полученное время жизни СК в клетках $(1.3 \mu \mathrm{s})$ находится в хорошем согласии с данными других авторов (от 0.4 до $1.7 \mu \mathrm{s}$ для разных типов клеток и разных фотосенсибилизаторов). Полученные результаты могут быть использованы для детального исследования фотодинамического воздействия на клетки.

\section{Конфликт интересов}

Авторы заявляют, что у них нет конфликта интересов.

\section{Список литературы}

[1] Niedre M., Patterson M.S., Wilson B.C. // Photochem. Photobiol. 2002. V. 75. N 4. P. 382-391.

[2] Jiménez-Banzo A., Sagristá M.L., Mora M., Nonell S. // Free Radical Biol. Med. 2008. V. 44. N 11. P. 1926-1934.

[3] Schlothauer J., Hackbarth S., Röder B. // Laser Phys. Lett. 2009. V. 6. N 3. P. 216-221.

[4] Hackbarth S., Schlothauer J., Preuß A., Röder B. // J. Photochem. Photobiol. B. 2010. V. 98. N 3. P. 173-179.

[5] Vyklický V., Dédic R., Curkaniuk N., Hála J. // J. Lumin. 2013. V. 143. P. 729-733. 
[6] Hatz S., Poulsen L., Ogilby P.R. // Photochem. Photobiol. 2008. V. 84. N 5. P. 1284-1290.

[7] Belik V.P., Gadzhiev I.M., Semenova I.V., Vasyutinskii O.S. // Spectrochim. Acta A. 2017. V. 178. P. 181-184.

[8] Belik V.P., Gadzhiev I.M., Petrenko M.V., Petrov M.A., Semenova I.V., Vasyutinskii O.S. // Chem. Phys. Lett. 2016. V. 665. P. $127-130$.

[9] Бельтюкова Д.М., Белик В.П., Васютинский О.С., Гаджиев И.М., Гончаров С.Е., Семенова И.В. // Оптика и спектроскопия. 2018. Т. 124. В. 1. С. 51-55.

[10] Belashov A.V., Zhikhoreva A.A., Belyaeva T.N., Kornilova E.S., Petrov N.V., Salova A.V., Semenova I.V., Vasyutinskii O.S. // Opt. Lett. 2016. V. 41. N 21. P. 50355038.

[11] Belashov A.V., Zhikhoreva A.A., Belyaeva T.N., Kornilova E.S., Salova A.V., Semenova I.V., Vasyutinskii O.S. // Proc. of SPIE. 2018. V. 10685. P. 1068505 (1-7).

[12] Biswas R., Moon J.H., Ahn J.-C. // Photochem. Photobiol. 2014. V. 90 . N 5. P. $1108-1118$. 